\title{
Managing salinity in degraded soils by mandatory tree planting: on dynamics and economic modeling of a common pool resource
}

\author{
E. A. Nuppenau \\ Department of Agricultural Economics, University of Giessen, Germany
}

\begin{abstract}
Many farming areas in the semi-arid tropics and sub-tropics are characterized by increasing salinity. Due to (1) the common property problem of the media, water, (2) high transaction costs in soil protection and (3) non-point-pollution problems, salinity is a common feature of poorly managed irrigation schemes. Environmental regulations, governing water use, and farm practices such as (1) limitations in water dosage, (2) specific plants mixes, etc., but also (3) regeneration of soils, by methods such as (4) fallowing, (5) tree planting, (6) applying gypsum, etc., are normally not in the direct interest of small-holder farmers. Such measures reduce current income and future benefits have to be shared. In contrast as a new idea, tree planting to extract salt and minimize shocks from droughts have gained the interest of salinity management, notably as a low cost and appropriate technology solution. This paper presents an innovative model that accounts for salinity in the short and long run; introduces mandatory tree planting to farmers for salinity reduction; and reckons current income waivers from reduced cropping for trees. A dynamic concept is used to control farm activities and cater for a reduction of salinity in communities. It models water tables, tree cover and salt content.
\end{abstract}

Keywords: tree planting, salinity, dynamic optimization.

\section{Introduction}

In irrigation projects the salinity of soils is a serious and complex problem for resource economics [1]. Salinity threatens agricultural production in many areas of the tropics and subtropics. Though gypsum application and leaching are possible treatments [2] they are mostly too expensive for farmers. However, salinity may change through soil improvements associated with fallowing and 
tree planting. Salinity is a non-point pollution problem, specifically in communities that share the soil as a common-pool property. A common property management problem therefore emerges. Tree planting seem to be not only a technical thing [3], rather it needs cooperation of farmers. Common property and tree planting management, together, should be viewed as interwoven tools for salinity control. The task is to extract salt from saline soils so that improvement occurs and costs of desalinization are minimized. The management and cleaning of a saline area, as to be understood in this paper, is a co-management consisting of long run benefits from reduced salt inflows and short run costs from restrictions in land use, detected as strips planted with trees [4]. Costs include planting and costs of cutting trees, and water evaporated by trees. Benefits include firewood and fruits.

The questions [5] are, (1) how soils improve, if a public will exists and optimizes actions; (2) how to implement public management; and how (3) to minimize free-riding as strategy. Also, what are ecological prerequisites, economic incentives and institutional needs to achieve improvements? For this and the purposes of the paper, a few assumptions are in order, (1) that an irrigation scheme, given a certain tree cover, has a potential to reduce salt, though only to a certain extent and a long run perspective is needed; (2) farmers have an interest in soil quality; (3) an institutional setting is agreed upon which solves problems of non-point pollution and common property; (4) in principle, we will hand over the task of improving soils to a common-pool property manager, whose task is to reduce the negative externality of salinity; and (5) the manager will be given the right to allocate trees. Then $\mathrm{s} /$ he maximizes social welfare, i.e. being a benevolent dictator.

It is the prime objective of the paper to show how tree planting can be an alternative to unsustainable practices. The method suggested is a dynamic economy model which depicts several small-scale farmers. The paper is organized in four sections. In Section 2 we will look at the dynamics of salinity. In section 3 we will state farmers' objective functions concerning waivers on land use. Section 4 will use this information to explore the dynamic behavior of tree growth, and in section 5 a control theory model shows how a particular soil improvement can occur.

\section{Dynamics of soil and land set-aside in smallholder agriculture}

The quality of the soil in a watershed or irrigation system shall be described by an index that measures the negative impact of salinity on the productivity of soils. As discussed elsewhere [1], a decline in soil quality associated with salinity has several implications for soils and farm productivity. Fundamentally soils are a public good and salinity is shared by farmers. The concentration of sodium can be used as a measurable variable for salinity; in principle sodium is accepted as major quantitative contributor to soil quality decline [2]. Sodium contents can change, and are subject to accumulation. This accumulation is stimulated by three components, (1) irrigation water use, (2) rise of water table, 
and (3) fertilization of the watershed. Farmers do not see salinity as non-pointpollution; for them it is only a by-product of irrigation. To present the dynamics of salinity in conjunction with farm activities and deduction of salty nutrients, we, as scientists, can use a first order differential equation (1) for the change of soil quality. We explicitly recognize land allocation for trees; i.e. tree planting is on land set-aside by farms.

$$
\dot{S}(t)=-\kappa_{0} S(t)+\kappa_{1} W(t)+\kappa_{2}\left[\sum_{j}\left(A^{t}-A_{j}\right)\right]+\kappa_{3}\left[O^{0}-O(t)\right]-\kappa_{4} l^{l}(t)
$$

Broadly, equation (1) recognises the dynamics of salinity $\mathrm{S}(\mathrm{t})$ as dependent on the water table "W", land allocation "A" and organic matter " 0 ". Land allocation, as one part, describes farming activity by area under crops $\left(A-\Sigma A_{j}\right)$ and area setaside (A, as second part). An explanation for the water table will follow later. Organics are given by area times stand of trees which changes equation (1) to (1')

$$
\Leftrightarrow \dot{S}(t)=-\kappa_{0} S(t)+\kappa_{1} W(t)+\kappa_{2} \sum_{j}\left[A^{t}-A_{j}\right]+\kappa_{3}\left[F^{0} \cdot A^{0}-F(t) \cdot A(t)\right]-\kappa_{4} l^{l}(t)
$$

where $\mathrm{S}(\mathrm{t})$ : soil quality index (sodium) at time $\mathrm{t}$ (can be sodium content: natural decrease)

$\mathrm{W}(\mathrm{t})$ : water table at time $\mathrm{t}$ (increase)

$A^{t}-A_{j}(t)$ : polluting acreage of farmers at given technology, i.e. irrigation use (increase)

$\mathrm{O}(\mathrm{t})$ : organic matter by growth in matter per hectare on communal fallow (decrease)

$A(t)$ : area under fallow of each farmer (decrease)

$1^{1}(t)$ : deliberate used water for leaching of water to combat salinity (decrease)

$\mathrm{F}(\mathrm{t})$ : organic matter per hectare

$\mathrm{A}^{0}$ : steady state fallow stand to offset salinity

Equation (1') describes a natural system, whereby salinity diminishes by natural leaching of soils due to rainfall, low water tables, etc. Vegetation is an amplifying measure for salt reduction. Upper and lower boundaries are specified for S. Presuming that decreasing salinity is associated with increasing prevalence of trees in the area, a first order differential equation with a coefficient of " $\kappa$ " below 1 implies that the soil is still capable of improving itself. Land set-aside plays a major role. For instance, presuming an approachable constant level of salinity at a certain size of natural vegetation, the value of " $\mathrm{A}^{0 "}$ can specify the steady state situation. Lowest salinity, from a modeling point of view is the steady state under the condition " $\kappa_{2}\left(\mathrm{~A}^{0}-\mathrm{A}(\mathrm{T})\right) / \kappa_{0}$ ", apparently, without agricultural use. Natural tree cover " $\mathrm{A}^{0 "}$ can be used for calibration of the lower bound of lowest salinity (upper end of soil quality). Special cases can be distinguished beside the natural situation. In the case of no land set-aside, " $\mathrm{A}=0$ ", farmland is maximized. This means apparently the model would move to an upper point of salinity $\left(\kappa_{1}\left[\Sigma \mathrm{A}^{*}{ }_{\mathrm{j}}-\mathrm{A}^{0}\right]+\kappa_{2} \mathrm{~A}^{0}\right) / \kappa_{0}$ ".

Equation ( $\left.1^{\prime}\right)$ is connected with the water table. By water infiltration, soils show, depending on local conditions, changes (rise) in water tables (after years of use). 


$$
\begin{gathered}
\dot{W}(t)=\zeta_{0}+\zeta_{1} W(t)+\zeta_{2}\left[\sum_{i}(1-z) l_{j}\right]+\zeta_{3}\left[F^{0} \cdot A^{0}-F(t) \cdot A(t)\right] \\
-\zeta_{4} F(t) \cdot A(t)+l_{m}^{l}(t)-l_{m}^{p}(t)
\end{gathered}
$$

where additionally: $1(\mathrm{t})$ : water not used in plant production, retained in soils at farm $\mathrm{j}$ in time $\mathrm{t}$

$\mathrm{Z}$ : technical factor on leaching

$l^{1}(t)$ : leaching water to clean surface soils from salt on a hectare basis

$1^{\mathrm{p}}(\mathrm{t})$ : water pumped out of the system with special technical devices

$\zeta_{0}$ : threshold of water table

In equation (2) inflows from leaching, evaporation by trees, and additionally a policy variable such as pumping groundwater change the table. We also assume a natural outflow given as an autonomous change of the system, and consider the possibility of making the function linear to distinguish water and land allocation:

$$
\begin{aligned}
\dot{W}(t) & =\zeta_{0}+\zeta_{1} W(t)+\zeta_{2}(1-z) \sum_{i}\left[l^{0}\left[A^{t}-A_{j}\right]+\left[A^{t}-A_{j}^{0}\right] l_{j}\right] \\
& +\zeta_{3}\left[F^{0} \cdot A(t)-A^{0} \cdot F(t)\right]-\zeta_{4} F(t) \cdot A(t)+l_{m}^{l}(t)-l_{m}^{p}(t)
\end{aligned}
$$

Next, organic matter content that perhaps does absorb salt and improves soil fertility is seen as a dynamic process. Organic matter, as quantity standing ready for extraction, supports desalinization of soils by filtering salt out of water. The filter potential is determined by the size of the biomass. Biomass enters our dynamic function $\left(1^{\prime}\right)$, and it is influenced by the water table. Loss or enrichment (change) of bio-mass " $O$ " is due to cutting of trees by farmer $\mathrm{j}$ on set-aside land $\mathrm{a}_{\mathrm{j}}(\mathrm{t})$. Finally building up organic matter (1) is described by a differential equation (3):

$$
\dot{O}(t)=-\varphi_{0} O(t)+\varphi_{1} \sum_{j} a_{j}(t)-\varphi_{2} \sum_{j} u_{j}(t)+\varphi_{3} W(t)
$$

As stated above, organics $\mathrm{O}$ are qualified as land set-aside multiplied by stands of trees per hectare "F" and area measured as hectare "A": That is, $\mathrm{O}=\mathrm{F} \cdot \mathrm{A}$. It follows:

$$
[F(t) \cdot \dot{A}(t)]=\varphi_{0}[F(t) \cdot A(t)]-\varphi_{1} \sum a_{j}(t)+\varphi_{2} \sum u_{j}(t)+\varphi_{3} W(t)
$$

where additionally $a_{j}(t)$ : individual cutting of bush and tree land set-aside: optimized

$\mathrm{u}_{\mathrm{j}}(\mathrm{t})$ : individual new set aside of small-holders to bush: mandatory regulated

After a calculus intended to reduce complexity and to focus on area in land setaside, and in particular assuming a constant growth of the existing trees, we get;

$$
\begin{aligned}
& F(t) \cdot \dot{A}(t)+\dot{F}(t) \cdot A(t)=-\varphi_{0}[F \cdot A(t)]+\varphi_{1} \sum_{j} a_{j}(t)-\varphi_{2} \sum_{j} u_{j}(t)+\varphi_{3} W(t) \\
& \dot{A}(t)=\left[\varphi_{0}-\xi\right] A(t)+\varphi_{2} \sum_{j} a_{j}(t)-\varphi_{2}^{*} \sum_{j} u_{j}(t)+1 / F_{0} e^{-\xi \cdot t}+\varphi_{3} W(t)
\end{aligned}
$$

Also, as revealed in equation (3"'), the initial expression of the dynamic condition (3) depicts collective action of communities; i.e. collectively decided 
adding of trees on land set-aside from farm land $u_{j}$. whereas cutting and use of wood are private. Farmers make decisions $a_{j}$-calculating statuses (benefits of cutting) of common pool- from which a negative externality, salinity, is derived as a stock.

\section{The farmers' objective functions}

The economic analysis starts with conditional farm behavior, since this provides the basis for the manager. The focus is on land use and cutting trees. The applied micro-theory is similar to Varian [6]. It focuses on constrained profit functions. With salinity, we distinguish between farming on a remaining field and afforested land. Farmers lose profits on set-aside land; see negative effects of regulating land use. Positive effects of setting aside land (e.g. higher local humidity and yields) appear, but should be distinguished from common property management. The adjusted total profit is calculated using crop yields and gross margins on farm $\mathrm{j}$. The policy variable, tree planting " $\mathrm{u}_{\mathrm{j}}$ ", might stretch as strip between fields. Combating salinity, a farmer, $j$, shall recognize salinity in the watershed as a public, given a profit function " $\mathrm{P}=\mathrm{P}\left(\mathrm{A}_{\mathrm{j}}, \mathrm{a}_{\mathrm{j}}, \mathrm{u}_{\mathrm{j}}, \mathrm{S}\right)$ ". Salinity "S" is a negative common property. Land set-aside appears because tree cover already improves the micro-climate. All individual farmers work with a time horizon " $T$ " and discount " $\rho$ ".

$$
\mathrm{P}_{\mathrm{j}}[0, \mathrm{~T}]=\int_{o}^{T} e^{-\rho t}\left\{P\left(A_{j}(t), a_{j}(t), u_{j}(t), S(t)\right)\right\} d t
$$

where additionally: $\mathrm{P}(\mathrm{t})$ : profit at time $\mathrm{t}$

The profit function needs an explicit specification of (1) land allocation, (2) gross margins, (3) waiver on land use, and (4) recognition of profits from commons.

$$
\begin{gathered}
\mathrm{P}_{\mathrm{j}}[0, \mathrm{~T}]=\int_{o}^{T} e^{-\rho t}\left\{p_{j}^{a} d_{j}^{*}\left[A_{j}^{0}-A_{j}(t)\right]\right. \\
\left.+p_{j}^{f} a_{j}(t)-C\left(d_{j}\left[A_{j}^{0}-A_{j}(t)\right], a_{j}(t), r(t), S(t), A_{j}(t), u_{j}(t), z_{j}\right)\right\} d t
\end{gathered}
$$

where additionally: increase: "介”" and decrease " $\downarrow$ "“:

$\mathrm{p}^{\mathrm{a}}=$ gross margins/hectare according to yields per hectare in agriculture, (profit $\Uparrow$ )

$\mathrm{p}^{\mathrm{f}}=$ gross margins per ton in sales of fallow products from tree cutting, (profit $\uparrow$ )

$\mathrm{r}^{\mathrm{f}} \quad=$ water price, $(\cos \mathrm{t} \uparrow)$

$\mathrm{d}_{\mathrm{j}} \quad=$ yields per hectare including size of the field, (profit $\Uparrow$ )

$\left(\mathrm{A}_{0}-\mathrm{A}_{\mathrm{j}}\right) \quad=$ acreage as area cropped, $\left(\right.$ profit $\uparrow_{\text {; }}$;

$\mathrm{a}_{\mathrm{j}}=$ acreage where trees are cut, newly cropped next period, (profit $\uparrow$ );

$\mathrm{C}()=$. cost functions of $\mathrm{q}_{\mathrm{j}}$ at fields with the yield $\mathrm{a}=\mathrm{q}_{\mathrm{ij}} / \mathrm{l}_{\mathrm{ij}}$, $($ cost $\Uparrow=>$ profit $\downarrow)$

$\left(1-\mathrm{A}_{\mathrm{j}}\right) \quad=$ production effect on unit costs (ambiguous) 


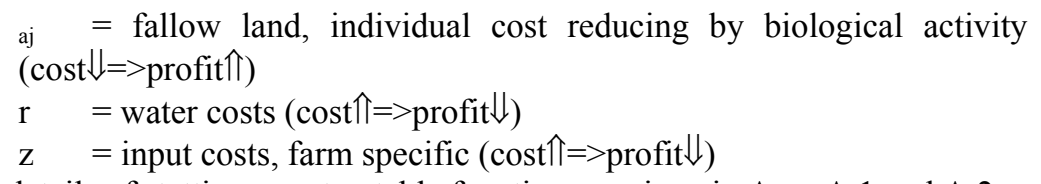

Further details of stetting up a treatable function are given in App. A.1 and A.2.

\subsection{Farm behavior}

Assuming (1) that there is homogeneity in land with respect to cost functions (A.1), which is explained in App.A.1; (2) equal time horizons for all farmers; and (3) interaction of profits with quality, i.e. substitution between other inputs and soil quality, as derived from salinity; the specification of profits (4') can be used for a dynamic farm optimization in the traditional sense. The mathematical tool [7] is a Hamiltonian (5) which is fully expressed in App.A.1 (for the complexity).

$$
\begin{aligned}
H_{j}(S, A, a) & =e^{-\rho t}\left\{p_{j}^{a} d_{j}^{*}\left(1-A_{j}(t)\right)+p_{j}^{f} a_{j}(t)-\left[. . S_{30} a_{j} . . A_{j}^{2} . . S_{j}^{2}\right]\right\} \\
& +L_{1}(t)\left[\varphi_{0} A(t)-\varphi_{1} a(t)+\varphi_{2} u(t)+\varphi_{3} W(t)\right]
\end{aligned}
$$

Equation ( 5 as A.5) is given by a quadratic expression. Since it is dynamic optimization we can use control theory [7] expressed as 3 criteria for a dynamic optima:

$$
H(t)_{A_{j}(t)}=-\dot{l}(t) \quad H(t)_{a_{j}(t)}=0 \quad H(t)_{l(t)}=-\dot{A}_{j}(t)
$$

With (5) and (6) we encounter individual rationality. As is shown in App. A.1 a system of equations gives an optimal compromise of immediate cash (short term benefits) and investments into soil quality (low salinity). Note land set-aside for salinity control is given exogenous as mandatory planting (to derive public benefits). The individual farm optimization of land use "A", including tree cutting is contingent. As solution we derive at equations (7a) and (7b). Comparable to incentive constraints in principal agent models, conditions (7a and b) depict behavior given "S", "W", and " $\mathrm{u}_{\mathrm{j}}$ ". An interesting feature of equations (7) is a dependency between land set-aside and salinity. Given different stages of salinity - guaranteed by an authority - a farmer has different incentives to invest in land set-aside:

$$
\dot{L}_{j}(t)=v_{10}^{*}+v_{11}^{*} L_{j}(t)+v_{12}^{*} A_{j}(t)+v_{13}^{*} S(t)+v_{14}^{*} W(t)+v_{15 j}^{*} u_{j}(t)+v_{16}^{*} r+v_{17}^{*} e^{\rho t}(7 \mathrm{a})
$$

where $\mathrm{L}$ is a shadow price and $\mathrm{A}$ the area under land set-aside (versus cropping)

$$
\dot{\mathrm{A}}_{\mathrm{j}}(\mathrm{t})=\mathrm{v}_{20}^{*}+\mathrm{v}_{21}^{*} \mathrm{l}_{\mathrm{j}}(\mathrm{t})+\mathrm{v}_{22}^{*} \mathrm{~A}_{\mathrm{j}}(\mathrm{t})+\mathrm{v}_{23}^{*} \mathrm{~S}(\mathrm{t})+\mathrm{v}_{24}^{*} \mathrm{~W}(\mathrm{t})+\mathrm{v}_{25}^{*} \mathrm{u}_{\mathrm{j}}(\mathrm{t})+\mathrm{v}_{26}^{*} \mathrm{r}+\mathrm{v}_{27}^{*} \mathrm{e}^{\mathrm{\rho t}}
$$

These equations apply to all farmers, which means the sum is $A=\Sigma A_{j}$ and $L=\Sigma L_{j}$. Equations (7) are also aggregated positions for a public good manager who wants to infer the tendency to cutting for wood and convert land previously setaside.

\subsection{System behavior}

By solving the system dynamics in the farm community, i.e. eliminating the result for the shadow price and tree cutting, we receive a movement of area under trees, 


$$
\dot{A}(t)=v_{20}+v_{22} A(t)+v_{23} S(t)+v_{24} W(t)+\sum_{j} v_{25 j}^{*} u_{j}(t)+\sum_{j} v_{26 j}^{*} e^{\rho t}
$$

and for conditions of soil quality we use our treatable linear differential equation

$$
\dot{S}(t)=-\kappa_{0} S(t)+\kappa_{1} W(t)+\kappa_{2}\left[\sum_{j}\left[A^{t}-A_{j}\right]+\kappa_{3}\left[F^{0} \cdot A^{0}-F(t) \cdot A(t)\right]-\kappa_{4} l^{l}(t)\right.
$$

which we simplify by condensing coefficients as the representation of the system

$$
\dot{S}(t)=v_{10}+v_{11} S(t)+v_{12} W(t)+v_{13} A(t)_{2}+v_{14} l^{l}(t)+v_{15} e^{\rho t}
$$

The differential equation ( $8 \mathrm{a}$ and $\left.b^{\prime}\right)$ has to be supplemented with the water table development. To do so we have to reconsider that the individual water use (A.9) is dependent on farm behavior and that cutting trees is a behavioral function depending on prices and structural variables. We start rewriting of equation

$$
\dot{W}(t)=\zeta_{0}^{*}+\zeta_{1}^{*} W(t)+\zeta_{2}^{*} A(t)+\zeta_{3}^{*} \sum_{i} l_{j}+\zeta_{14} e^{\rho t}+l_{m}^{l}(t)-l_{m}^{p}(t)
$$

Then, finally, the effect of the internal optimization of water " $\mathrm{l}_{j}$ " use (App. A.1. Eq. A.2) on a farm, using the behavior model (App. A.1), can be described as

$$
\begin{aligned}
\dot{W}(t)= & v_{30}+v_{31} W(t)+v_{32} A(t)+v_{33} S(t)+\sum_{j} v_{34 j} u_{j} \\
& +v_{35} x(t)+\zeta_{35} e^{\rho t}+v_{35 j} l_{m}^{l}(t)+v_{36 j} l_{m}^{p}(t)
\end{aligned}
$$

Note the water table development is no longer a pure physical process rather the inclusion of explanatory equations " $x$ " (A.9) determines water infiltration. The procedure results in a deliberately modifiable behavior of water tables, being new.

\section{Social welfare function and optimization}

In the case of a benevolent manager (maximizing social welfare) welfare is the sum of individual welfare (Bentham's utilitarian perspective). The manager of an irrigation scheme should seek to maximize benefits for his/her clients, regardless of distribution consequences. Besides maximizing the short term benefits, $\mathrm{s} / \mathrm{he}$ should balance them with long term impacts from sustaining soil quality (apparently combating salinity). From a perspective of the management of soil salinity, the task is to create an inter-temporal welfare function which includes all members of the community. We may formally represent the problem of the manager as:

$$
W_{[0, T]}=\sum_{j} P_{j,[0, T]}
$$

Drawing on the above representation of individual profit functions $P_{j}$, we can establish the problem as a temporal optimization problem of allocating land to be set aside to individual farmers. It is easiest if we start with identical farmers. Presuming " $n$ " identical farmers and optimizing over a horizon 0 to $T$, we get the objective function (10). Using similar arguments, as given above for gross margins (4') and cost functions (A.1), given an agreed time horizon (T) in terms of integrating long term welfare arguments, uniform time preference $\mathrm{e}^{\rho \mathrm{t}}$, and recognizing the temporal development of salinity from equations $(8 \mathrm{a}, 8 \mathrm{~b}$ ', and 
$8 c^{\prime}$ ), we receive an optimal control problem [7] in equation (10) for a benevolent dictator:

$$
\begin{aligned}
& \mathrm{W}[0, \mathrm{~T}]=\int_{o}^{T}\left\{e ^ { - \rho t } \sum _ { j } \left\{P\left(A_{j}(t), u_{j}(t), S(t), W(t)\right)-P_{j}^{w} l_{m}^{l}-P_{j}^{e} l_{m}^{p}+\Lambda_{1}(t)\left[v_{10}\right.\right.\right. \\
& \left.+v_{13} A(t)+v_{11} S(t)+v_{12} W(t)+v_{14} l_{m}^{l}(t)+v_{15} e^{\rho t}\right]+\Lambda_{2}(t)\left[v_{20}+v_{21} A(t)\right. \\
& \left.+v_{22} S(t)+v_{23} W(t)+v_{14} u+v_{25} e^{\rho t}\right]+\Lambda_{3}(t)\left[v_{30}+v_{32} A(t)+v_{33} S(t)\right. \\
& \left.\left.+v_{31} W(t)+v_{34} u+l_{m}^{l}(t)-l_{m}^{p}(t)+\zeta_{35} e^{\rho t}+v_{3} r(t)\right]\right\} d t
\end{aligned}
$$

where additionally: $\mathrm{p}^{\mathrm{w}}$ : water price

$\mathrm{p}^{\mathrm{c}}$ : pumping costs

Note most prominent, in this objective function the dynamic criteria for system behavior (8a, 8b', 8c') appear as dynamic Lagrange conditions which provide shadow prices $\Lambda(\mathrm{t})$. To add this specification of the temporal management problem by a benevolent dictator, equation (10) includes land allocation " $\mathrm{A}$ " as major state variable and for control " $\Sigma v_{\mathrm{j}} \mathrm{u}_{\mathrm{j}}$ " " (i.e. tree land given constraint is " $A$ ", and " $A$ " $-A$ " is cropped land). Further state variables are salinity "S" and water table "W". Newly assigned land, to be set-aside, afforested, is $\Sigma v_{\mathrm{j}} \mathrm{u}_{\mathrm{j}}$, and it is an instrument variable. Costs contain costs for planting. Trees are cut accordingly and "S" changes.

Additionally in the objective, opportunity costs of water $\mathrm{p}^{\mathrm{w}}$, which might be used for leaching, have to be deducted, notably, on the basis of an equilibrium price for fresh water in the watershed. We take a given water price for fresh water which is used from a source outside the system. And, we can also include pumping costs or additionally external costs for salty water $\mathrm{p}^{\mathrm{c}}$. In case of no external effects of water pumped out of the system, pure pumping costs are relevant. In case of down stream problems with water, external costs have to be included. The management problem is solved by control theory [7] as function (A.12):

Again using standard mathematics to solve dynamic optimization problems the control problem has now to fulfill 9 conditions for the dynamic maxima (11):

$$
\begin{aligned}
& H(t)_{A(t)}=-\dot{\Lambda}_{1}(t), H(t)_{S(t)}=-\dot{\Lambda}_{2}(t), H(t)_{W(t)}=-\dot{\Lambda}_{3}(t), H(t)_{u_{j}(t)}=0, H(t)_{l_{m}(t)} \\
& =0, H(t)_{l_{p}(t)}=0, H(t)_{\Lambda_{1}(t)}=-\dot{A}(t), H(t)_{\Lambda_{2}(t)}=-\dot{S}(t), H(t)_{\Lambda_{3}(t)}=-\dot{W}(t),
\end{aligned}
$$

These are nine criteria for a Hamiltonian (see A.12) of the objective function (10). Then we can retrieve, as a result, a system of equations. The system is explicitly documented in Appendix A.3 (A.13). The manager controls afforestation, land use, salinity, water table, and leaching; he also recognizes system effects receiving shadow prices. The problem, comprising six differential equations, has to be solved for endogenous variables y (App.7.3 where $y=[A(t)$, $\left.\mathrm{S}(\mathrm{t}), \mathrm{L}(\mathrm{t}), \mathrm{u}(\mathrm{t}), \mathrm{l}_{1}(\mathrm{t}), \mathrm{l}_{\mathrm{p}}(\mathrm{t}), \Lambda_{1}(\mathrm{t}), \Lambda_{2}(\mathrm{t}), \Lambda_{3}(\mathrm{t})\right]^{\prime}$ given exogenous variables (see lists of variables).

$$
\dot{y}(t)=a+A y(t)+B x(t)
$$


The manager solves equation (12). Apparently, further analysis will provide system behavior like steady states, dynamics of salt and sizes of public intervention.

\section{Results and conclusions}

As a result of the modeling, irrigation system managers are given an analytical tool to combat salinity in the long run. The system (12) can be solved for time dependent paths on the stage variable: (1) soil quality as an index for salinity, $\mathrm{S}(\mathrm{t})$ ); (2) land set-aside, hence also agricultural area, $\mathrm{A}_{0}-\mathrm{A}(\mathrm{t})$; and (3) the water table, $W(t)$. For paths to reach envisaged steady states, the control variables $u(t)$, $1(t)$ and $l_{p}(t)$ provide necessary annual instructions on mandatory tree planting, leaching and pumping as publicly controlled. Fundamentally the model implicitly caters for tree cutting on farmland $a_{j}(t)$ since private behavior is anticipated. The results are watershed related. They are dependent on the composition of the farm sector; i.e. the system (12) is a corner solution of an institution, characterized as a benevolent manager, but it could also be applied to a large farm which wants to optimally recognize soil quality dynamics. The aspect of many farms, being involved in common-pool-property management, has not been tackled.

\section{A Appendix}

\section{A.1 Individual optimization}

Using land allocation as a constraint for farm behavior, the intention of the following intermediate analysis is to explain the cutting- and land-clearingbehavior of individual farms. Farms are primarily interested in crop land and not tree covered land; considering an advantage of firewood if prevalent, perhaps lower salinity is given. Clearing of land for cropping is an instantaneous exercise. It occurs even if mandatory tree planting is a policy instrument of a public manager. Clearing provides land for farm surplus. This can be modeled: To make the analysis operational, we will introduce a quadratic cost function (A.1) to equation (4').

$$
\begin{gathered}
\mathrm{P}_{\mathrm{j}}[0, \mathrm{~T}]=\int_{0}^{T} e^{-\rho t}\left\{p_{j}^{a} d_{j}^{*}\left[A_{j}^{0}-A_{j}(t)\right]+p_{j}^{f} a_{j}(t)\right. \\
\left.-C\left(d_{j}\left[A_{j}^{0}-A_{j}(t)\right], a_{j}(t), r(t), S(t), A_{j}(t), u_{j}(t), z_{j}\right)\right\} d t
\end{gathered}
$$

In quadratic cost functions (A.1) interactions are presumed; then (A.1) is inserted.

$$
\begin{aligned}
& C\left(d_{j}^{*}\left(A_{j}^{o}-A_{j}\right), S(t), r, a_{j}, u_{j}, r_{j}\right)=\gamma_{10} A_{j}+\gamma_{20} S+\gamma_{30} a_{j}+\gamma_{40} u_{j}+0.5 \gamma_{11} A_{j}^{2} \\
& +0.5 \gamma_{22} S^{2}+0.5 \gamma_{33} a_{j}^{2}+0.5 \gamma_{44} r_{j}^{2}+0.5 \gamma_{55} u_{j}^{2}+\gamma_{12} A_{j} S+\gamma_{13 j} A_{j} a_{j}+\gamma_{14 j} A_{j} u_{j} \\
& +\gamma_{23} S u_{j}+\gamma_{24} S a_{j}+\gamma_{34 j} a_{j} u_{j}+\gamma_{31} r A_{j}+\gamma_{32} r S+\gamma_{33 j} r a_{j}+\gamma_{34 j} r u_{j}
\end{aligned}
$$


Next we can use Shepherd's Lemma to derive water demand per hectare which is:

$$
l_{j}=\gamma_{44} r_{j}+\gamma_{31} A_{j}+\gamma_{32} S+\gamma_{33 j} a_{j}+\gamma_{34 j} u_{j}
$$

This equation can be inserted in the water table differential equation (8c') to reveal a dependency of the water table on the demand for water. Also the production of $\mathrm{j}$ is determined by the marginal revenue minus the cost, giving farm sizes:

$$
\begin{aligned}
& p_{j}^{a} d_{j}^{*}-\gamma_{10}+\gamma_{11} A_{j}+\gamma_{12} S+\gamma_{13 j} a_{j}+\gamma_{14 j} u_{j}+\gamma_{31} r=0 \Rightarrow \\
& q_{j}^{s}=d_{j}\left[A_{j}^{0}-A_{j}\right]=d_{j}\left[A_{j}^{0}-\gamma_{11}^{-1}\left[\gamma_{10 j}^{*}-p_{j}^{a} d_{j}+\gamma_{12} S+\gamma_{13 j} a_{j}+\gamma_{14 j} u_{j}+\gamma_{31} r\right]\right]
\end{aligned}
$$

In (A.3) yields per hectare are not yet defined, but we can determine them as

$$
d_{j}=\xi_{j} l_{j}=\xi_{j}\left[\gamma_{44} r_{j}+\gamma_{31} A_{j}+\gamma_{32} S+\gamma_{33 j} a_{j}+\gamma_{34 j} u_{j}\right]
$$

Note, we have specified the cost function as determined by state variables of the system "S" and by several behavioral equations. However, farmers do not only behave statically with respect to water demand, given state variables, etc., rather they decide on dynamics: tree planting, duration and cutting of trees, etc. Equation (6 equal to A.5) serves the optimization criteria of a Hamilton function [7]:

$$
\begin{aligned}
& H_{j}(S, A, a, t)=e^{-\rho t}\left\{p_{j}^{a} d_{j}^{*}\left[1-A_{j}(t)\right]+p_{j}^{f} a_{j}(t)-\left[\gamma_{10} A_{j}+\gamma_{20} S+\gamma_{30} a_{j}+\gamma_{40} u_{j}\right.\right. \\
& +0.5 \gamma_{11} A_{j}^{2}+0.5 \gamma_{22} S^{2}+0.5 \gamma_{33} a_{j}^{2}+0.5 \gamma_{44} r_{j}^{2}+0.5 \gamma_{55} u_{j}^{2}+\gamma_{12} A_{j} S+\gamma_{13 j} A_{j} a_{j} \\
& +\gamma_{14 j} A_{j} u_{j}+\gamma_{23} S u_{j}+\gamma_{24} S a_{j}+\gamma_{34 j} a_{j} u_{j}+\gamma_{31} r A_{j}+\gamma_{32} r S+\gamma_{33 j} r a_{j} \\
& \left.\left.+\gamma_{34 j} r u_{j}\right]\right\}+L_{1}(t)\left[\varphi_{0} A(t)-\varphi_{1} a(t)+\varphi_{2} u(t)+\varphi_{3} W(t)\right]
\end{aligned}
$$

Using control theory [7], as mentioned, the three criteria for dynamic optima are

$$
H(t)_{A_{j}(t)}=-\dot{l}(t) \quad H(t)_{a_{j}(t)}=0 \quad H(t)_{l(t)}=-\dot{A}_{j}(t)
$$

Applying (6) to (A.5) provides conditions of dynamic behavior on land set-aside:

$$
\begin{gathered}
+\gamma_{11} \mathrm{~A}_{\mathrm{j}}(\mathrm{t})+\gamma_{13} \mathrm{a}_{\mathrm{j}}(\mathrm{t})+[\beta-\rho] \cdot \mathrm{L}(\mathrm{t})=-\dot{\mathrm{L}}(\mathrm{t})+\gamma_{10}-\mathrm{d}_{\mathrm{j}}^{*} \mathrm{p}_{\mathrm{j}}^{\mathrm{a}}+\gamma_{12} \mathrm{~S}(\mathrm{t})+\gamma_{14 \mathrm{j}} \mathrm{u}_{\mathrm{j}}(\mathrm{t})+\gamma_{31} \mathrm{r} \\
\gamma_{13} A_{j}(t)+\gamma_{33} a_{j}(t)-\varphi_{1} L(t)=p_{j}^{f}+\gamma_{24} S(t)+\gamma_{34 j} u_{j}+\gamma_{33 j} r \\
\varphi_{0} \mathrm{~A}_{\mathrm{j}}(\mathrm{t})+\varphi_{1} \mathrm{a}_{\mathrm{j}}(\mathrm{t})-\varphi_{2} \mathrm{u}_{\mathrm{j}}(\mathrm{t})+\varphi_{3} \mathrm{~W}(\mathrm{t})+1 / \mathrm{F}_{0} \mathrm{e}^{-\xi \mathrm{t}}=-\dot{\mathrm{A}}_{\mathrm{j}}(\mathrm{t})
\end{gathered}
$$

After internal solving system (A6) for differentials 2 differential equations prevail:

$$
\begin{aligned}
& \dot{L}_{j}(t)=v_{10}^{*}+v_{11}^{*} L_{j}(t)+v_{12}^{*} A_{j}(t)+v_{13}^{*} S(t)+v_{14}^{*} W(t)+v_{15 j}^{*} u_{j}(t)+v_{16}^{*} r+v_{17}^{*} e^{\rho t} \\
& \dot{A}_{j}(t)=v_{20}^{*}+v_{21}^{*} l_{j}(t)+v_{22}^{*} A_{j}(t)+v_{23}^{*} S(t)+v_{24}^{*} W(t)+v_{25}^{*} u_{j}(t)+v_{26}^{*} r+v_{27}^{*} e^{\rho t}
\end{aligned}
$$

\section{A.2 Deriving system relevant behavioral equations}

Next we need the water demand function

$$
l_{j}=\gamma_{44} r_{j}+\gamma_{31} A_{j}+\gamma_{32} S+\gamma_{33 j} a_{j}+\gamma_{34 j} u_{j}
$$

again and solve it simultaneously with the cutting tree function. 


$$
a_{j}=\frac{1}{\gamma_{33}}\left[p_{j}^{f}+\gamma_{24} S(t)+\gamma_{34 j} u_{j}(t)+\gamma_{43 j} r_{j}(t)+\varphi_{1} L_{j}(t)+\gamma_{13} A_{j}(t)\right]
$$

Inserting the cutting of tress incentive function into water demand we receive

$$
\begin{aligned}
& l_{j}=\gamma_{44} r_{j}+\gamma_{31} A_{j}+\gamma_{32} S+\gamma_{33 j} \frac{1}{\gamma_{33}}\left[p_{j}^{f}+\gamma_{24} S(t)+\gamma_{34 j} u_{j}(t)+\gamma_{43 j} r_{j}(t)+\varphi_{1} L_{j}(t)\right. \\
& \left.+\gamma_{13} A_{j}(t)\right]+\gamma_{34 j} u_{j}
\end{aligned}
$$

which is a function of state variables $A$ and $S$, and the control variable $u$, plus exogenous variables. Note further the sum of water applied in fields, as provided by farmers and also delivered, is an estimation of water used in plant production. This can be important for a calculation of water available for leaching.

$$
\begin{aligned}
& l_{m}^{l}=\sum_{j} l_{j}=\sum_{j}\left[\gamma_{44} r_{j}+\gamma_{31} A_{j}+\gamma_{32} S+\gamma_{33 j} \frac{1}{\gamma_{33}}\left[p_{j}^{f}+\gamma_{24} S(t)+\gamma_{34 j} u_{j}(t)+\gamma_{43 j} r_{j}(t)\right.\right. \\
& \left.\left.+\varphi_{1} L_{j}(t)+\gamma_{13} A_{j}(t)\right]+\gamma_{34 j} u_{j}\right]
\end{aligned}
$$

By these exercises the number of variables can be reduced to core variables.

\section{A.3 Optimizing of management for salinity control in the watershed}

Given farm behavior a to be explicated function, optimized, taken above costs, is:

$$
\begin{gathered}
\left.\left.W=e^{-\rho t} \int_{o}^{T}\left\{\sum_{j}\left\{p_{j}^{a} d_{j}^{*}\left[A_{j}^{\rho}-A_{j}(t)\right]+p_{j}^{f} a_{j}(t)-C\left(d_{j}\left[A_{j}^{0}-A_{j}(t)\right], a_{j}(t), r(t), S(t), A_{j}(t), u_{j}(t), z_{j}\right)\right\}+P_{j}^{e}\right]\right\}\right\} d t \\
\text { s.t } \quad \dot{S}(t)=v_{10}+v_{13} A(t)+v_{11} S(t)+v_{12} W(t) \quad+v_{14} l_{m}^{l}(t) \quad+v_{15} e^{\rho t} \\
\dot{A}(t)=v_{20}+v_{21} A(t)+v_{22} S(t)+v_{23} W(t)+\sum_{j} v_{14 j} u_{j} \quad+v_{25} e^{\rho t} \\
\dot{W}(t)=v_{30}+v_{32} A(t)+v_{33} S(t)+v_{31} W(t)+\sum_{j} v_{34 j} u_{j}+l_{m}^{l}(t)-l_{m}^{p}(t)+\zeta_{35} e^{\rho t}+v_{3} r(t)
\end{gathered}
$$

and

$$
a_{j}=\frac{1}{\gamma_{33}}\left[p_{j}^{f}+\gamma_{24} S(t)+\gamma_{34 j} u_{j}(t)+\gamma_{43 j} r_{j}(t)+\varphi_{1} L_{j}(t)+\gamma_{13} A_{j}(t)\right]
$$

where $\mathrm{L}(\mathrm{t})$ is practically given by an internal determination of all shadow prices. As discussed in equation (7b) it includes a determination by $\mathrm{S}(\mathrm{t})$ and stands alone

$$
L(t)=v_{10}^{* *}+v_{11}^{*} A(t)+v_{12}^{*} S(t)+v_{13}^{*} W(t)+\sum_{j} v_{14 j}^{*} u_{j}(t)+\sum_{j} v_{15 j}^{*} e^{\rho t}+v_{16}^{*} r(t)
$$

in a steady state. We now take a sector- or watershed-wide approach with "n" identical farmers, which implies: (1) control conditions (11) are applied to the function (A.10), (2) we resume a non-varying cost function (a quadratic function provides linear derivatives with similar coefficients, (3) and the cost function of 
(A.1) rechecks cross effects. With $\mathrm{n}$ farmers and instruments $\Sigma \mathrm{u}_{\mathrm{j}}=\mathrm{n} \cdot \mathrm{u}$, inserted in (A.10), we get a Hamiltonian (A.12) of 3 state variables and 3 control variables:

$$
\begin{aligned}
& H\left(A, S, W, u_{j}, l_{m}, l_{p}, t\right)=e^{-\rho t}\left\{P ^ { * } \left[\gamma_{44} r_{j}+\gamma_{31} A(t)+\gamma_{32} S(t)+\gamma_{33 j}\left[\gamma_{00}^{*} A(t)+\gamma_{02}^{*} S(t)\right.\right.\right. \\
& \left.\left.+\gamma_{03}^{*} W(t)+\gamma_{04} u(t)+\gamma_{05}^{*} r\right]+\gamma_{34 j} u(t)\right][1-A(t)]-\left[[ \gamma _ { 1 0 } ^ { * } - P _ { j } ^ { f } ] \left[\gamma_{00}^{*} A(t)+\gamma_{02}^{*} S(t)\right.\right. \\
& \left.+\gamma_{03}^{*} W(t)+\gamma_{04} u(t)+\gamma_{05}^{*} r\right]-0.5 \gamma_{11}^{*} A^{2}(t)-0.5 \gamma_{11}^{*} S^{2}(t)-0.5 \gamma_{44} u^{2}(t)+\gamma_{12}^{*} A(t) S(t) \\
& \left.+\gamma_{14 j}^{*} A(t) u(t)+\gamma_{23} S(t) u(t)-P_{j}^{w} l_{m}^{l}-P_{j}^{e} l_{m}^{p}\right\} d t+\Lambda_{1}(t)\left[v_{10}+v_{13} A(t)+v_{11} S(t)\right. \\
& \left.+v_{12} W(t)+v_{14} l_{m}^{l}(t)+v_{15} e^{\rho t}\right]+\Lambda_{2}(t)\left[v_{20}+v_{21} A(t)+v_{22} S(t)+v_{23} W(t)+v_{14} u\right. \\
& \left.+v_{25} e^{\rho t}\right] \Lambda_{3}(t)\left[v_{30}+v_{32} A(t)+v_{33} S(t)+v_{31} W(t)+v_{34} u+v_{35} l_{m}^{l}(t)+v_{36} l_{m}^{p}(t)\right. \\
& \left.+\zeta_{35} e^{\rho t}+v_{3} r(t)\right]
\end{aligned}
$$

Then the results after getting the derivatives for the state and control variable are:

$$
\begin{gathered}
P_{a}^{*} \gamma_{31}^{*}-\left[\gamma_{10}^{*}-P^{f}\right] \gamma_{00}^{*}+\left[P_{a}^{*} \gamma_{33}^{*} \gamma_{00}^{*}+\gamma_{00}^{*}\right] A(t)+\gamma_{12}^{*} S(t)+v_{14}^{*} u(t)+v_{13} \Lambda_{1}(t)+v_{21}^{*} \Lambda_{2}(t) \\
+v_{32}^{*} \Lambda_{3}(t)=\dot{\Lambda}_{1}(t)-\rho \Lambda_{1}(t) \\
P_{j}^{f} \gamma_{32}^{*}+\left[\gamma_{10}^{*}-P^{f}\right] \gamma_{02}^{*}-\left[\gamma_{33}^{*} \gamma_{02}^{*} P_{j}^{f}+\gamma_{12}^{*}\right] A(t)-\gamma_{11}^{*} S(t)-\gamma_{14}^{*} u(t)+v_{11}^{*} \Lambda_{1}(t)+v_{22}^{*} \Lambda_{2}(t) \\
+v_{11}^{*} \Lambda_{3}(t)=\dot{\Lambda}_{2}(t)-\rho \Lambda_{2}(t) \\
{\left[\gamma_{10}^{*}-P^{f}\right] \gamma_{03}^{*}-\gamma_{33}^{*} \gamma_{03}^{*} P_{j}^{f} A(t)+v_{12}^{*} \Lambda_{1}(t)+v_{23}^{*} \Lambda_{1}(t)+v_{31}^{*} \Lambda_{3}(t)=\dot{\Lambda}_{3}(t)-\rho \Lambda_{3}(t)} \\
{\left[\gamma_{40 j}^{*}-p_{j}^{f}\right]+\gamma_{00} \gamma_{04} A(t)+\gamma_{44} u(t)+\gamma_{14}^{*} A(t) n \gamma_{23} S(t)+v_{24 n}^{*} \Lambda_{2}(t)+v_{34}^{*} \Lambda_{3}(t)=0} \\
p^{w}+v_{14 n}^{*} \Lambda_{1}(t)+\Lambda_{3}(t)=0 \\
p^{e}+\Lambda_{3}(t)=0 \\
v_{10}+v_{13} A(t)+v_{11} S(t)+v_{12} W(t)+v_{14} l_{m}^{l}(t)+v_{15} e^{\rho t}=\dot{S}(t) \\
v_{20}+v_{21} A(t)+v_{22} S(t)+v_{23} W(t)+v_{14} u+v_{25} e^{\rho t}=\dot{A}(t)
\end{gathered}
$$

To solve the system, variables are put as $\mathrm{y}$ and $\mathrm{x}$ and we obtain a system solution:

$$
\dot{y}(t)=a+A y(t)+B x(t)
$$

where: $y$ is a vector $=\left[\mathrm{A}(\mathrm{t}), \mathrm{S}(\mathrm{t}), \mathrm{L}(\mathrm{t}), \mathrm{u}(\mathrm{t}), \mathrm{l}_{1}(\mathrm{t}) \mathrm{l}_{\mathrm{p}}(\mathrm{t}), \Lambda_{1}(\mathrm{t}), \Lambda_{2}(\mathrm{t}), \Lambda_{3}(\mathrm{t})\right]^{\prime}$ and $\mathrm{x}$ $=[\mathrm{p}, \mathrm{r}, \ldots]$

\section{References}

[1] Gretton, P., Salma, U., Land degradation: links to agricultural output and profitability. Australian Journal of Agricultural and Resource Economics, 41 (2), 1997, 209-225.

[2] Qadir, M., S. Schubert, A. Ghafoor und G. Murtaza, Amelioration strategies for sodic soils: A review. Land Degradation Development, 12, 2001, 357-386. 
[3] Barrett-Lennard, E.G., Restoration of saline land through revegetation. Agricultural Water Management, 53, 2002, 213-226.

[4] Tanji, K.K., Karajeh, F.F., Saline drain water reuse, in Agroforestry Systems. Journal of Irrigation and Drainage Engineering. 119 (1), 1993, 170-180.

[5] Wichelns, D., An economic model of waterlogging and salinization in arid regions. Ecological Economics, 30, 1999, 475-491.

[6] Varian, H.L. Micro Economics, Amsterdam, 1994.

[7] Tu., P.N.V. Introductory Optimization Dynamics. Berlin, 1992. 